\title{
A Lesson Plan of TBLT (Task-Based Language Teaching)
}

\author{
Jiang Ting \\ Office of Academic Affairs, Huainan Normal University, Huainan, China
}

\section{Email address:}

ge_jiangting@163.com

\section{To cite this article:}

Jiang Ting. A Lesson Plan of TBLT (Task-Based Language Teaching). International Journal of Secondary Education.

Vol. 4, No. 3, 2016, pp. 32-38. doi: 10.11648/j.ijsedu.20160403.12

Received: September 30, 2016; Accepted: November 9, 2016; Published: November 10, 2016

\begin{abstract}
This article demonstrates a task-based language teaching class in Chinese context, and it follows the three-stage TBLT framework: pre-task; task cycle and the language focus. Rationale for TBLT method; authentic teaching material and specific activities involved in the class have been explained and justified. Finally, it critically evaluates the designed lesson plan in accordance with Chinese context and indicates potential difficulties with practical consideration.
\end{abstract}

Keywords: Task-based Language Teaching, Lesson Plan, Activities, Authentic

\section{Introduction}

In this article, a lesson plan has been designed in accordance with TBLT (task-based language teaching) and has been evaluated from theoretical and practical perspectives. Nowadays, though TBLT has been extensively discussed and researched in literature, practically, it has been faced with a few difficulties in the process of real teaching. Due to practical limitations, for example, students and teachers are not familiar with TBLT, especially for teachers, it is hard for them to adapt the teaching material in line with TBLT. What is more, be faced with pressure of passing the exam, some students are unwilling to acclimatize themselves to the new method. Furthermore, it is highly recommended by the Ministry of Education that TBLT should be implemented in secondary school for the sake of effective teaching and teacher-student interaction. Therefore, the lesson plan designed in this article aims to provide a TBLT model in real Chinese context as a reference for English teachers and EFL teaching. Additionally, it has been critically evaluated for acknowledging some limitations of lesson plan and providing implications for further teaching and relevant study.

This article consists of two main parts: rationale and evaluation of lesson plan. Rationale provides detailed definitions of task, justification for task-based language teaching (TBLT), then follows a series of specific activities and reasons for choices of these activities. The second part evaluation covers a range of topics ranging from advantages of TBLT, evaluation of authentic material and particular activities involved in this lesson.

\section{Rationale for TBLT}

Numerous definitions of "task" have been provided by different scholars, and each definition has its own focus. Nunan [27] classifies "task" into pedagogical tasks (occur in classroom) and real-world tasks or target tasks (occur beyond the classroom). Five dominant characteristics of task are summarized as follows: TBLT is meaning-focused; instead of repeating what other people say, learners are expected to produce language; has connection with real-world tasks; assessed in accordance with outcome. A large body of literature provides theoretical rationale for TBLT. Lynch and Maclean [20] advocate TBLT by providing two primary reasons: first, classroom task imitates and promotes performance in real world task. Second, drawing on SLA research, the issue of 'learnability', the developmental sequence for L2 acquisition, input and output hypothesis have provided implications and justification for TBLT. Skehan [37] pointed out that as an approach to instruction, task-based teaching is theoretically justifiable and flexible in implementation. TBLT favors implicit instruction by the way of "learning through doing activities or tasks" [31]. It is contended that TBLT provides improved and supportive conditions for developing second language ability than other approaches which relies heavily on explicit teaching on language structure [18]. 


\section{Main Ideas on Lesson Plan}

The lesson is designed for Chinese senior high students who are prepared to go abroad. The lesson lasts for around 1hour and 45 minutes. The objectives of this lesson follows four strands: to make full use of lyrics to expand vocabulary; to develop scanning strategy and intensive reading; to develop speaking fluency by maximizing speaking opportunities; to promote target culture awareness and interest. Regarding their learning outcomes, firstly, students will be able to pronounce every word in lyrics correctly. Secondly, students will be able to speak their own interpretations of this song. Thirdly, students will be able to complete reading comprehension sheet. The only teaching material involved in the lesson is the music The sound of silence.

\subsection{Lyrics as Authentic Material}

Nunan [26] points out a collection of key components of task: input, activities, goal, roles, and settings. Here music is not merely used as language input but also stimulus for eliciting emotion and entailing experience. A significant rationale for using music lies in affective factors involved in language learning and teaching. Krashen's "affective filter" hypotheses demonstrated that low affective filter can promote language learning. Music has the capacity of relaxing mind and increasing retention of learned knowledge [23]. Gardner's Theory of Multiple Intelligences also supports the effectiveness of music in Second language acquisition. According to this psychologist, he asserts that every human possesses eight distinct intelligences, and music intelligence is intimately linked to language intelligence. Music is strongly recommended to be introduced into language class from the perspective of psychology. Therefore, music as teaching material for second language acquisition echoes both linguistic and psychological theory and empirical research.

\subsection{Classroom Organization}

Classroom environment is an important element for effective learning [45]. A classroom full of desks and chairs can be both psychological and physical obstacle for effective communication. Consequently, all desks and chairs are removed and the class is organized like "horseshoe" shape with the teachers sitting at the mouth.

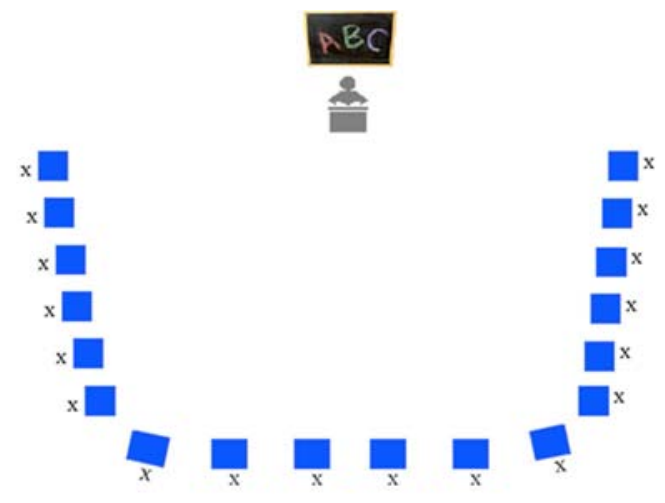

Figure 1. "horseshoe" shape seating arrangement.

\section{Framework for TBLT}

Since TBLT has been recognized as one of favorable and authentic way of teaching, several frameworks for TBLT have been advocated and highly approved in literature. In this article, a framework suggested by Willis [46] has been adopted and implemented in the lesson.

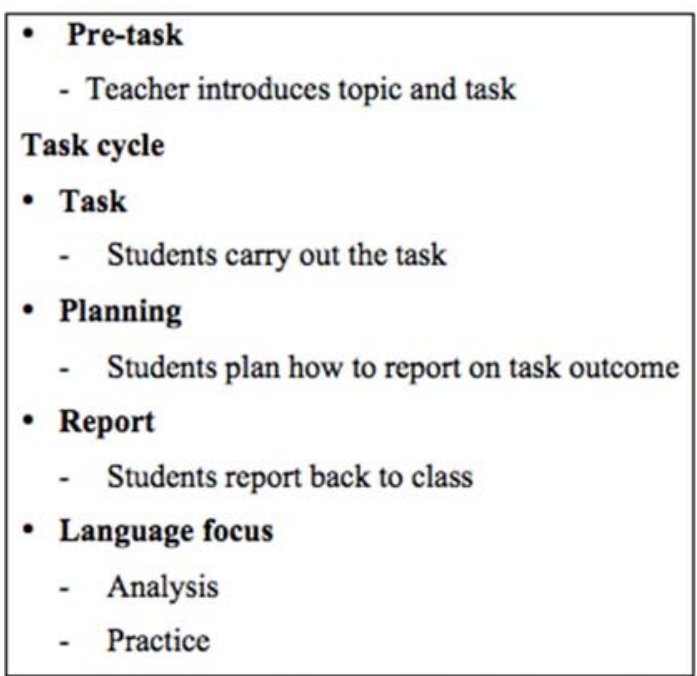

Figure 2. A framework for TBLT (Willis, 1996).

\subsection{Pre-task Phase}

Pre-task stage function as preparation for real task implementation. It consists of introducing topic, activating prior knowledge and giving task instructions. Sufficient conditions for language learning are exposure, use and motivation [46]. Pre-task activities aim to provide adequate listening and reading input and motivate learners through fabulous music and stimulating activities.

According to the principle of task dependence, a series of activities are designed from easy to more challenging one. In line with receptive-to-creative principle, speaking and role play are placed after reading and listening activities [27]. In activity 1 , the primary reason for playing instrumental version is to free learners from struggling with language, to set the mood for subsequent activities. According to Suggestopedia principle, learners are totally immersed in rhythm without external interference, which makes them more susceptible to language input and increases their attention [23]. Attention is key element for triggering learning, and developing attention span is considered as a vital instruction task [35]. Apart from functioning as warm-up activity, the prediction element in this activity may inspire learners' curiosity, which sets purpose for later listening activity. Referential questions play important role in eliciting comprehensible output and further dialogue between teachers and students [21]. Referential question [19] is defined as question introduced by teacher without specific answer (i.e. what is your overall feeling about this song?). However, research indicated that learners with low performance respond passively to referential questions [21]. Therefore, scaffolding is needed to draw learners' attention 
and continue the task. Scaffolding is defined as external help happened during other-regulated interactions [27]. It serves six main functions: engage students into task; divide task into manageable parts, make task doable; motivate learners to continue task; guide learners' attention to specific activities; reduce learners' anxiety during task; strive for better outcome [47]. It is obvious that from task sequence to emotion control, the concept of scaffolding is throughout whole instruction. In activity 2 , learners compare the initial speculation with what they have comprehended from listening and add signal words to justify their choice [43]. After the listening, they check information with partner to discuss what question need further attention in later reading activity [42]. Task difficulty hinges on familiarity with topic and the cognitive demands of task type [46]. To reduce the cognitive load, music is played without showing lyrics. In activity 3 , reading music review sample can be classified as 'mining' stage, whereby learners select useful language input for subsequent output activities [46]. Simultaneously, scanning skill is considered as a efficient vehicle for lengthy text. It is defined as locating key words or required specific information rapidly in the text [38]. Reading follows closely listening, and such a repeated exposure to same material provides support for higher performance in task cycle [25].

\subsection{Task Cycle}

After adequate preparation, at task cycle stage, learners are expected to use whatever language to complete the task with specific objectives. It is composed of three components: task; planning; report. Task implementation is the starting point and planning comes next as the central part, finally report serves to be a stimulus for whole task completion [46]. Due to the complexity of the task, time leaving for planning is longer than task itself. At planning stage, learners have to make decisions about what to report and check language forms. In activity 4 and 5, learners are expected to critically analyze the content of lyrics through intensive reading. The activity involves consensus-building, during which group members have to decide on final theme and mood of this music. It aims to engage students into discussion and provide the opportunity for further dialogue. To prolong communication time is a basic concern for oral practice [28]. To arrive agreement within group, several rounds consensus building initiates deeper thinking [11]. In activity 6 , picture cues extracted from lyrics are provided for constructing storyline for later activities. Memory research also indicates that picture is more memorable than words. Sequence task here functions as facilitating task, making following challenging task easier [46]. In activity 7, there are two options for learners: reconstruct lyrics into story or evaluate this song. Both are open tasks without specific outcome which give learners greater flexibility. Task is classified according to different cognitive skills, and each type of task presents various degree of linguistic challenge. Considering the practicality of mixed ability class, two options are given for tailoring learners with different English levels. Choice also exerts positive effect on motivation [4]. Role play has been practiced in conversation class for a long period of time, it maximally reflects real-like circumstance by introducing roles in life. Additionally, it is a stimulating means for spontaneous speaking [1]. Finally, it enables learners to demonstrate sociopragmatic and pragmalinguistic knowledge through communication [40]. In activity 8, peer feedback is introduced for saving time and increasing speaking time. Additionally, research also indicates the effectiveness of peer feedback in classroom instruction [34]. Feedback from classmates increases possibility of self-correction and autonomous learning [48].

\subsection{Language Focus Phase}

The desirable condition for effective language learning is explicit instruction [46]. This stage is designed for summarizing language structures elicited during task cycle. It is accepted that language instruction causes higher degree of satisfaction and speeding up the language development [27]. By systematizing language used in task cycle, learners are asked to take notes about interesting points and useful phrases during reporting stage. Adding vocabulary into notebook is one effective learning strategy [44]. In question C, learners are asked to search figurative language, the prominent feature of this song, then create similar sentences. The answer will be given at the end of class, after the practice, learners will cross check answers within groups. The practice of cross-checking further generates speaking opportunity. Memory challenge at language focus section is used as consolidation and review what has been covered in this lesson. In order to make full use of lyrics, repeated exposure to vocabulary items also adds possibility of incidental learning [36]. Competition for jigsaw game is a good integration of competition and cooperation element in constructing activities, and it contributes to higher performance motivation level [41].

\section{Evaluation of the Lesson Plan}

This sections aims to critically analyze the activities and authentic material adopted in this lesson plan against the background of Chinese secondary school. Firstly, evaluate TBLT application in Chinese context; secondly, analyze the benefits and weakness of introducing authentic material into second language instruction; finally, specifically evaluate the activities and texts involved in this lesson from the perspective of applicability and potential challenges.

\subsection{TBLT in China}

Proponents of TBLT maintain that traditional approach to language teaching fails to accommodate learners' needs and language is regarded as the goal of teaching. TBLT is a needs-based approach with clear outcome and flexibility. Besides, Language is considered as tool for communication. TBLT as a creative approach has achieved the pedagogical shift from teacher-centered to student-oriented teaching [49]. In China, though the implementation of TBLT is government-mandated, conflicting values and starkly different teacher-student relationship impede the application 
of TBLT [13]. Under the great influence of Confucius heritage, teachers dominate classroom and undertake the main task of transmitting knowledge in China. However, TBLT has its roots in Western culture, learners pursue knowledge through doing activities [27]. Therefore, it is of great importance to specify roles of teachers and students during instruction process. In Willis's framework for TBLT, role of instructor has been explicitly indicated in specific stages. For example, in task cycle, teacher plays role of monitor, chairperson and language adviser respectively at task, planning and reporting stage [46]. While for learners, they are language users with active participation in task implementation rather than passive recipients of knowledge. Role transition presents challenges both for teachers and learners.

\subsection{Authentic Material}

The terms "authenticity" and application of authentic material in second language teaching are subjects of discussion. Authentic material refers to original material from real scenario without further adaption for pedagogical use [32]. Authentic material in multiple forms (audio, video, text) activates the mental processing and durable memory [23]. In this lesson, audio, written text and pictures are provided. However, there are criticism exist for adopting authentic material when compared with created material. Created material is organized around graded syllabus which provides learners with systemized knowledge points. Besides, it is a burden for teachers to select authentic material and to design appropriate activities tailoring to learners' proficiency level [32].

Table 1. Advantages and disadvantages of authentic material.

\begin{tabular}{|c|c|}
\hline Advantages & Disadvantages \\
\hline Stimulating elements in music & Redundant language in lyrics \\
\hline Authentic sample of target culture & $\begin{array}{l}\text { Burden for teachers to select } \\
\text { appropriate teaching materia }\end{array}$ \\
\hline $\begin{array}{l}\text { Bountiful resource online } \\
\text { contributes to self-direction } \\
\text { learning }\end{array}$ & $\begin{array}{l}\text { Distraction caused by the } \\
\text { accompanying music }\end{array}$ \\
\hline
\end{tabular}

Nowadays, Internet and self-direction learning style prompts the learners' expectation for authentic material. Adequate music resources are free to choose from, and music the sound of silence is introduced here for its rich culture specific elements and relatively high quality of language in lyrics. There are several advantages of introducing music into classroom. Firstly, music adds stimulating element in language teaching; secondly, repetitive language and melody leads to higher retention rate; thirdly, authentic sample of target culture; finally, bountiful resource online [22]. However, the quality and genre of music language is varied, when compared with poetry, language of song seems redundant. Selecting appropriate music presents to be a great task for teachers [23]. It takes me hours to search this music for teaching material. What is more, deficient knowledge of background information of music may decrease learners' confidence or lead to false interpretations of lyrics. As discussed before, the close relationship between schemata knowledge and reading comprehension justifies the necessity of intensive reading in pre-task stage. Due to the fact that Chinese students are not very used to task-based teaching, therefore, the task instruction is suggested to be given orally and in written form.

\subsection{Activities and Class Management}

One crucial element in task is instruction setting. It includes the learning mode and environment [27]. Starting from this perspective, "horseshoe" shape classroom organization and diverse learning modes such as pair, individual and group are good practices of creating harmonious environment [27]. Group work is one of effective teaching strategy through which learners can discuss common problems, pool thoughts together and construct new ideas [9]. In China, some teachers refute the group work for difficulty of control. Comparatively, pair work ensures the equal participation of each learner and effectively avoids "free rider" problem. Particular activity which requires checking comprehension and private thinking is more suitable for individual learning mode. Consequently, for different task types, learning mode changes accordingly (i.e. answer reading comprehension question individually; discuss in pair; complete task in group). Some introverted students may be unwilling to participate in group work initially, thereby instructors are supposed to observe from a distance and encourage them to undertake individual responsibility. Activities designed follow key principle of task continuity, for example, "static" task (matching pictures with words in lyrics) precedes "abstract" task (constructing story); jigsaw games combined with visual support (pictures) provide contextual cues for constructing story. At the beginning of class, playing instrumental version of music is one effective way to increase attention span. Researchers have developed the idea that the amount of attention largely decides to what extent the input and interaction transform into intake [24]. It is possible that learners may be detracted by accompanying music. Accordingly, learning goal should be acknowledged antecedently. Goal-directed activity is perceived to increase learners' attention [15]. Referential question has the capacity of eliciting longer responses and more grammatically complex sentence compared with display question [2]. It is claimed that referential question generates natural and more authentic answer from learners [5]. However, some research concerning the relationship between question type and learners' output indicates that only high level students can benefit from complicate question type [29]. Therefore, in order to boost learners' confidence at the beginning of class, referential questions are simple broad questions (i.e. what Is your favorite music type?). Repeated exposure through receptive skills (listening and reading) on the one hand, it maximizes the opportunity of practicing intensive listening and scanning strategy in reading. On the other hand, it makes learners familiarize with topic of following task. The input hypothesis also supports the idea of receptive skills before productive skill in the language acquisition [16]. Research also demonstrates that effective vocabulary learning can take place with adequate listening and reading practice especially if teacher select particular vocabulary items first, then write 
them on board [7]. Reading music review is intentionally inserted into pre-task section to provide model for task completion. Open task (construct story from lyrics) which needs deeper processing of text and retrieval of pre-selected word can result in "comprehensible output" [39]. By providing alternative for task, it opens up opportunity for group decision-making and reduces anxiety of learners resulted from challenging task.

Most scholars maintained that vocabulary is mostly acquired from extensive reading [14] In this process, vocabulary is conceived to be the by-product of reading activity. It is called incidental vocabulary learning which has several advantages over the intentional teaching. Firstly, contextualized teaching offers rich meaning of vocabulary; secondly, reading and vocabulary learning can take place simultaneously; finally, learners are free to select useful words from target text. However, there are some key questions remain unsolved relating to this strategy such as exact word range for inferring; guessing strategy; what kind of exposure is effective. Furthermore, there are several unavoidable problems with this technique: guessing is not reliable when exact understanding of text is needed; it slows down the reading speed [12].

Scanning skill as a vital sub-skill of reading is frequently used in real-life situations. Teaching reading strategy is suggested to be combined with extensive reading [6]. The practice of selecting one or two interesting points in task performance is to motivate learners to make further progress [46]. Positive feedback sustains learners' interest in continuing task. Inevitably, incomplete feedback information fails to objectively reflects learners' real level. Therefore, peer feedback is integrated into this lesson. Instead of correcting errors in public by teacher, errors are expected to be solved within group. Language practice is identifying figurative language and changing ends of phrases. Apart from incremental vocabulary acquisition, it also direct learners' attention to features of music language.

At last, all learners are asked to sing the song together. This activity not only contributes to group solidarity [23], but also checks answers of memory challenge activity in a stimulating way. Furthermore, this activity also practices pronunciation of every word in this song. Potential challenge is that learners are new to this song, and they may feel embarrassed to sing it aloud. Finally, before the homework, there is time leaved for self-reflection and asking question. In other words, learners can make full use of time to clarify obscured concepts, unknown words, tease out key language points and digest learned knowledge. Since this activity is placed at the end of class, learners may be reluctant to raise questions. If this happens, teachers can prepare some questions beforehand. As for the homework, it has been the old debate over the necessity of homework. Good and Brophy maintained that homework is the continuity of learning opportunity in class [2]. Homework is also a form of formative assessment which could be used to keep track of learners' progress and efficacy of instruction [32]. However, criticism of homework largely derives from its quantity and quality. Too much homework adds burden on learners even leads to resistance of schooling. What is more, In Chinese secondary school, homework is compulsory and usually takes form of memorization and recitation, which conflicts with tenet of TBLT teaching, In order to overcome these weakness, homework in this lesson consists of two parts: search information online; write a short music review. Music review is used as checking effectiveness of learning and teaching, and the other activity is a typical one used in TBLT.

\section{Conclusion}

Though the lesson plan has been discussed in a detailed way, it still subjects to modification during the process of instruction rather than remain as fixed model. Learning process is far more important than end product-lesson plan [32]. It is noted that key components of lesson plan play important role in real instruction (lesson aims; learning outcome; anticipated problem).

This lesson follows three-stage TBLT framework with integration of key principles extracted from other advocates of TBLT. The rationale consists of key concepts in lesson plan and the justification for all choices made in this framework. The second part evaluation follows clear threads of TBLT, authenticity, vocabulary and activities.

\section{References}

[1] Aliakbari, M., \& Jamalvandi, B. (2010). The Impact of" Role Play" on Fostering EFL Learners' Speaking Ability: A Task-Based Approach. Journal of Pan-Pacific Association of Applied Linguistics, 14(1), 15-29.

[2] Brock, C. A. (1986). The effects of referential questions on ESL classroom discourse. TESOL quarterly, 20(1), 47-59.

[3] Brophy, J. (2003). Teaching Problem Students. Guilford Press.

[4] Cooper., H., Patall, E. \& Wynn, S. "The Effectiveness and Relative Importance of Choice in the Classrom." Journal of Educational Psychology, 102.4 (2010).

[5] Dalton-Puffer, C. (2007). Discourse in Content and Language Integrated Learning (CLIL) Classrooms (Vol. 20). John Benjamins Publishing.

[6] Day, R. R. and Bamford, J. (1998). Extensive Reading in the Second Language Classroom. Cambridge University Press.

[7] Elley, W. B. (1989). Vocabulary Qcquisition From Listening To Stories. Reading Research Quarterly, 174-187.

[8] Fluckiger, J., Vigil, Y., Pasco, R., \& Danielson, K. (2010). Formative Feedback: Involving Students as Partners in Assessment to Enhance Learning. College Teaching, 58 (4), 136-140.

[9] Forslund Frykedal, K., \& Chiriac, E. H. (2014). Group work management in the classroom. Scandinavian Journal of Educational Research, 58(2), 222-234.

[10] Hao, P. (2013) A Survey of the Implementation of Task-Based Approach in Senior High School English Teaching Shandong Normal university. 
[11] Haruma, H., \& Christopher, L. (2011). Western and Japanese Discourse Style in a Consensus-Building Task Discussion. Pan-Pacific Association Of Applied Linguistics (PAAL), 15(1), 39.

[12] Haynes, M., \& Baker, I. (1993). American and Chinese Readers Learning from Lexical Familiarizations in English text. In T. Huckin, M. Haynes, \& J. Coady (Eds.), Second language Reading and Vocabulary Learning (pp. 130-152). Norwood, NJ: Ablex.

[13] Hu, R. (2013). Task-Based Language Teaching: Responses from Chinese Teachers of English. Tesl-Ej, 16(4), n4.

[14] Huckin, T., \& Coady, J. (1999). Incidental Vocabulary Acquisition in a Second Language. Studies in second language acquisition, 21(02), 181-193.

[15] Kane, M. J., \& Engle, R. W. (2003). Working-Memory Capacity and the Control of Attention: the Contributions of Goal Neglect, Response Competition, and Task Set to Stroop Interference. Journal of Experimental Psychology: General, 132(1), 47.

[16] Krashen, S. D. (1985). The Input Hypothesis: Issues and Implications (Vol. 19850). London: Longman.

[17] Laufer, B. (1997). The Lexical Plight in Second Language Reading: Words you Don't Know, Words you think you know, and Words you can't Guess. In J. Coady \& T. Huckin (Eds.), Second Language Vocabulary Acquisition: A Rationale for Pedagogy (pp. 20-34). New York: Cambridge University Press.

[18] Long, M. H. (1985). A Role for Instruction in Second Language Acquisition: Task-based Language Teaching. In K. Hyltenstam, \& M. Pienemann (Eds.), Modeling and accessing second language acquisition (pp. 77-99). Clevedon: Multilingual Matters.

[19] Long, M. (1970). H. \& Sato, CJ (1983). Classroom Foreigner Talk Discourse: Forms and Functions of Teachers' Questions. Classroom Oriented Research in Second Language Acquisition, 3-34.

[20] Lynch, T., \& Maclean, J. (2000). Exploring the Benefits of Task Repetition and Recycling for Classroom Learning. Language Teaching Research, 4(3), 221-250.

[21] McNeil, L. (2012). Using Talk to Scaffold Referential Questions for English Language Learners. Teaching And Teacher Education: An International Journal Of Research And Studies, 28(3), 396-404.

[22] Millington, N. T. (2011). Using Songs Effectively to teach English to young learners. Language Education in Asia, 2(1), 134-141.

[23] Mishan, F. (2005). Designing Authenticity into Language Learning Materials. Intellect Books.

[24] Mitchell, R., Myles, F., \& Marsden, E. (2013). Second Language Learning Theories. Routledge.

[25] Nation, I. S. P., \& Newton, J. (2008). Teaching ESL/EFL Listening and Speaking. Routledge:

[26] Nunan, D. (1989). Designing Tasks for the Communicative Classroom. Cambridge: Cambridge University Press.

[27] Nunan, D. 2004, Task-Based Language Teaching, Cambridge: Cambridge University.
[28] Oxford, R. L., 1990: Language Learning Strategies: What Every Teacher Should Know. Boston: Heinle \& Heinle.

[29] Özcan, 2010 Özcan, S. (2010). The Effect of Asking Referential Questions on the Participation and Oral Production of Lower Level Language Learners in Reading Classes. Unpublished master's thesis. Middle East Technical University.

[30] Prabhu, N. S. (1987). Second Language Pedagogy. Oxford: Oxford university press.

[31] Rahimpour, M. (2008). Implementation of task-based approaches to language teaching. Pazhuhesh-e-Zabanha-ye Khareji Journal, University of Tehran, 41, 45-61.

[32] Richards, J. C. (2001). Curriculum development in language teaching. Cambridge University Press. Cambridge.

[33] Robinson, P. (2001b). Task complexity, task difficulty, and task production: Exploring interactions in a componential framework. Applied Linguistics, 27-57. http://dx.doi.org/10.1093/applin/22.1.27.

[34] Rollinson, P. (2005). Using peer feedback in the ESL writing class. ELT Journal, 59(1), 23-30.

[35] Rost, M., \& Wilson, J. (2013). Active Listening. Harlow, UK: Pearson Education.

[36] Schmitt, N. (2008). Review article: Instructed Second Language Vocabulary learning. Language Teaching Research, 12(3), 329-363.

[37] Skehan, P. 1998. A Cognitive Approach to Language Learning. Oxford: Oxford Univerisity Press.

[38] Simensen, A. M. (2007). Teaching a Foreign Language Principles and Procedures (2ed.). Oslo: Fagbokforlaget.

[39] Swain, M. (1985) Communicative competence: Some roles of comprehensible input and comprehensible output in its development. In Gass, S. and Madden, C. (Eds.), Input in Second Language Acquisition, pp. 235-256. New York: Newbury House.

[40] Tatayama, Y. (1998). Explicit and implicit teaching of pragmatic routines: Japanese Sumimasen. In K. R. Rose \& G. Kasper (Ed.),

[41] Tauer, J. M., \& Harackiewicz, J. M. (2004). The Effects Of Cooperation and Competition on Intrinsic Motivation and Performance. Journal of Personality and Social Psychology, 86(6), 849.

[42] Vandergrift, L. (2003a). From Prediction Through Reflection: Guiding Students Through The Process of Second Language Listening. The Canadian Modern Language Review, 59(3), 425-440.

[43] Vandergrift, L., \& Tafaghodtari, M. (2010). Teaching Students How to Learn Does Make a Difference. Language Learning, 60(2), 470-497.

[44] Walters, J., \& Bozkurt, N. (2009). The Effect of Keeping Vocabulary Notebooks on Vocabulary Acquisition. Language Teaching Research, 13(4), 403-423.

[45] Waring, M. (2014). Teaching and Classroom. Learning to Teach: A Handbook for Primary and Secondary School Teachers, 102. 
[46] Willis, J. (1996). A Framework for Task-Based Learning. Harlow: U.K. Longman Addison-Wesley.

[47] Wood, D., Bruner, J., \& Ross, G. (1976). The role of tutoring in problem solving. Journal of Child Psychology and Psychiatry, $17,89 \mathrm{e} 100$.

[48] Zhang, S. (2011). Peer Feedback: A New Approach to English
Writing Instruction in a Chinese College Setting. Sino-US English Teaching, 8(6), 364-368.

[49] Zhang, X., \& Hung, S. (2013). A Case Study of Exploring Viability of Task-Based Instruction on College English Teaching in Big-Sized Class. Journal Of Language Teaching And Research, (4), 693. 